\title{
Interdisciplinary teaching of Statistics
}

\author{
$\underline{\text { E. Stojanovski }}$ \\ Discipline of Statistics, School of Mathematical and Physical Sciences, The University of Newcastle, \\ New South Wales \\ Email: elizabeth.stojanovski@newcastle.edu.au
}

\begin{abstract}
While the understanding of statistics is essential for model developers and users in a range of areas, the teaching of this content is not without its challenges. Teaching the next generation requires the employment of suitable core teaching practices to motivate and thus better support integrated resource management in terms of developing and using statistical models. Teaching statistics often involves teaching end users from multiple disciplines simultaneously.
\end{abstract}

There are often varying views among students undertaking statistics based courses of what statistics actually is and how it can be used in other courses of their degree and in the workplace such as in resource management. Feedback and attitudes of some students towards statistics subjects can be quite negative. The negative attitude could be due to a number of factors including the quality of previous exposure to statistics or mathematics or limited recognition of the role of statistics in other disciplines.

From an interdisciplinary perspective, there is an increased need to motivate students to want to learn statistics and hence a focus on developing methods to achieve positive outcomes in interdisciplinary statistics. This paper proposes four teaching strategies designed to motivate students, make content more relevant to them and thus improve their learning and teaching outcomes.

Clarifying the purpose of statistics to students both in society and for their specific disciplines is crucial and can be elaborated on in the first lecture in an attempt to capture engagement early. Creating an active learning environment to engage students' interest and extend on their understanding is also fundamental. Another principle to motivate students to learn is via the use of examples to which students can relate. These examples should include real world and current events to try to make links with students' interests and backgrounds. Employment examples should also be used for immediate relevance.

From an interdisciplinary perspective, the core practices described have been employed in the classroom environment in an attempt to improve students' statistical knowledge and to consequently be able to better develop and use models to support integrated resource management. The proposed strategies were implemented in first and second year interdisciplinary statistics courses and have been received favourably by students in terms of improving the relevance of interdisciplinary statistics courses as well as the students' overall satisfaction with the course, which are the initial steps required to consequently improve student learning outcomes among the next generation of learners.

Keywords: $\quad$ Mathematics, statistics, student engagement, teaching 


\section{INTRODUCTION}

In any university, the statistics content covered in many programs is considered important for the purpose of improving the critical analytical ability of students and applying this knowledge and set of skills to real applications, particularly in the respective disciplines. It is intended to assist students become better users and examiners of information as well as to improve career opportunities.

A statistics course thus often represents a core course in a range of undergraduate programs across different schools and faculties. While the understanding of statistics is essential for model developers and users in a range of areas, effective teaching of this content is vital. Teaching the next generation requires the employment of suitable core teaching practices to motivate and thus better support integrated resource management in terms of developing and using statistical models.

At the first year level, statistics courses often focus on servicing a range of different programs simultaneously while also sometimes representing the first component of a statistics major. The same course is thus offered to a diverse cohort of students, ranging from those undertaking Mathematics, Science, Psychology, Education as well as various Health Sciences, among others. Teaching statistics to end users from multiple disciplines simultaneously can be challenging.

\section{STUDENT PERCEPTIONS}

\subsection{Perceptions of Statistics}

There are often varying views among students of what statistics actually is and how it can be used in other courses of their degree and in the workplace.

Students are often not presented with a broad understanding of the role of statistics in core university subjects. Although the statistics subjects form part of a single (or double) degree, some students consider the course as somewhat mutually exclusive to their other courses while some believe the sole purpose of the courses is to be able to memorise different formula to enable passing of the final exam, also known as the 'rote learning approach', in order to obtain their degree (Devlin, 2002).

Feedback from students can be positive at the time of delivery and sometimes in later years when students advise how valuable the course was in subsequent studies and in the workplace. Statistics education is, however, often not well received by all students, with feedback and attitudes of some students quite negative (Schutz et al. 1998).

\subsection{Reasons Contributing to Negative Perceptions}

It is well known that undergraduates can lack engagement with statistics (Kember and McNaught, 2007). Students can be less motivated by courses with course codes not specific to their program and can view the topics of these courses as less relevant than those offered by their own disciplines, particularly for courses related to mathematics.

Students starting their degrees without strong mathematics foundations could also be a contributing factor. It has been reported that mathematics ability relates to performance in a statistics course (Schutz et al. 1998).

There is often a wide range of mathematics abilities among students given that mathematics is often not a formal requirement for many degrees. There can be diversity both in terms of when a mathematics course was last studied prior to commencing the degree, as well as the level of mathematics last studied. While some students begin their tertiary studies having completed mathematics subjects during their later years of secondary education, other students may not have studied mathematics since early high school; while other students may commence their tertiary studies after completing other academic qualifications such as bridging courses.

There is also disparity in the level of Mathematics covered between different subjects offered at secondary school. It is no longer a requirement that high school students study any mathematics for the $\mathrm{f}$, inal year of high school, potentially increasing the time since mathematics was last studied among recent school leavers. Nonetheless, extra resources are often implemented to aid in reducing the knowledge gap of students so that the required standard of courses at tertiary level is met. 


\section{METHODS TO IMPROVE STUDENT OUTCOMES}

Some have reported post statistics course improvements in the level of students' reasoning abilities (Ragasa, 2008) while other research has shown no statistically significant changes in students' reasoning skills despite receiving good grades in the course (Hirsch and O'Donnell, 2001). There is an increased need to develop methods to achieve positive outcomes in interdisciplinary statistics courses. The approach proposed in this paper is to focus on teaching practices that motivate students, make content relevant and make use of real life and current examples that link theory with practice.

\subsection{The First Lecture}

It is assumed that students understand the importance or purpose of statistics but this assumption is not guaranteed while the competency of student's statistics skills is limited (Reid and Petocz, 2002). Clarifying the purpose of statistics to students both in society and for their specific disciplines is crucial. The first lecture is perhaps the most important lecture as it sets the scene for entire semester and is an opportunity to capture the interest of students early. A technique utilised by the author is to ask students during this lecture their interpretation of what statistics is and the purpose of statistics in their disciplines. A list is generated based on the responses. Normally there is a limited number of responses and those provided are often formula related, for example, "statistics is about calculating the average". This exercise then provides the opportunity to elaborate on the responses and explain the role of statistics as dealing with uncertainties in the real world as opposed to just a group of formulas.

\subsection{Active Learning Environment}

Creating an active learning environment to engage students' interest and extend on their understanding involves the teacher's role moving from that of an instructor to that of a facilitator (Reid and Petocz, 2003). Students become more involved in their learning by the creation of an interactive setting (Oswald 1996). One tactic the author has used to help achieve this setting includes asking open-ended questions (for example, 'why is statistical significance important' as opposed to 'what level do we typically set the statistical significance to'). Other students then have the opportunity to respond to student queries before the instructor responds. Students are guided to answer questions with the use of leading questions. Furthermore, interactive resources help to teach and learn statistics by helping to gain a broader understanding of statistical concepts (Graham et al. 2003). For example, in a second year course taught by the author, the use of interactive handheld devices known as clickers in the past two years during lectures has received positive feedback from students. These clickers were incorporated into lectures to revise content on a weekly basis and to provide staff with a means to interactively poll students with multiple choice questions to gauge understanding and provide students with immediate feedback. The hand held device comprises a separate button for responses 1-10 respectively denoting A-J respectively. Upon viewing a multiple choice question, students are asked to select the response using the hand held device for the best answer. As responses are anonymous, students tend to be more encouraged to participate. Responses are automatically collated using the corresponding software and displayed directly to students via a computer.

\subsection{Use of Real and Current Examples}

Another principle to motivate students to learn is via the use of examples to which students can relate. The presentation of applications using various sources including real world examples, current events and current studies reported in newspapers, The intention is to try to make links with students' interests and backgrounds to keep them engaged. West et al. (1991) describe the use of metaphors as teaching techniques to enable students to apply previous knowledge to new concepts. As an illustration, the analogy 'innocent until proven guilty' to demonstrate the concept of no effect in hypothesis testing is often used by statisticians.

\subsection{Discipline Specific and Workplace Examples}

It has been proposed that curriculum should cater to the variation in student conceptions and should help to broaden their awareness of statistics (Slotnick et al. 1993). The author of the present paper often asks students to think ahead to life after their degree when a prospective employer may ask about the relationship between various types of therapy and clinical outcomes, for example, and then goes on to explain the importance of having a set of statistical tools that can be utilised to address this question, irrespective of the discipline in question. The importance of becoming evaluators and users of information is stressed throughout the course so that students are better equipped when leaving the University, again irrespective of the discipline being studied. Students are encouraged to read discipline specific journal articles with the aim 
of being able to generalise to beyond the data being presented to real life meanings. How statistics ties in with other courses within the degree, life in general and the workplace should be the focus of teaching statistics and therefore core modeling practices to the next generation.

\section{DISCUSSION AND CONCLUSIONS}

While the understanding of statistics is essential for model developers and users in a range of areas, teaching the next generation requires the employment of suitable core teaching practices to motivate and thus better support integrated resource management in terms of developing and using statistical models. Teaching statistics often involves teaching end users from multiple disciplines simultaneously. There is an increased need to motivate students to want to learn statistics and hence to focus on developing methods to achieve positive outcomes in interdisciplinary statistics.

From an interdisciplinary perspective, the core practices described should be employed in the classroom environment in an attempt to improve students' statistical knowledge and to consequently be able to better develop and use models to support integrated resource management. Clarifying the purpose of statistics to students both in society and for their specific disciplines is crucial and can be elaborated on in the first lecture in an attempt to capture engagement early. Creating an active learning environment to engage students' interest and extend on their understanding is also fundamental. Another principle to motivate students to learn is via the use of examples to which students can relate. These examples should include real world and current events to try to make links with students' interests and backgrounds. Employment examples should also be used for immediate relevance.

The proposed strategies were implemented in first and second year interdisciplinary statistics courses and have been received favourably by students. Collectively, the four teaching strategies proposed appear to have been successful in terms of motivating students and making content more relevant, which, consequently should allow for a greater potential to improve learning and teaching outcomes. This is evident from improved course feedback scores and student outcomes from qualitative student feedback comments. There was a notable improvement in the student satisfaction with course scores as well as for the relevance of course scores. Qualitative feedback includes 'Ability to keep everyone focused through use of Statistic related anecdotes and puns', 'Relates everything to statistics', 'helps the student understand how wide spread the content and course is'. None of the techniques appear to have been more or less effective than the other techniques; rather, the techniques implemented appear to complement each other in terms of keeping students engaged with content with the intention to ultimately improve student learning outcomes among the next generation of learners. 


\section{REFERENCES}

Devlin M. (2002). Taking responsibility for learning isn't everything: A case for developing tertiary students' conceptions of learning. Teaching in Higher Education 7:125-137.

Graham P., Notz W., Pearl D., Stansy E. (2003). Electronic resources: the Ohio state university EESEE project. Journal of Applied Mathematics and Decision Sciences 7: 85-92.

Hirsch L. and O’Donnell M. (2001). Representativeness in statistical reasoning: identifying and assessing misconceptions. Journal of Statistics Education 9: 2.

Kember D. and McNaught C. (2007). Enhancing University Teaching: Lessons from Research into Award Winning Teachers, Routledge, London.

Oswald P. A. (1996). Classroom use of the personal computer to teach statistics. Teaching of Psychology 23: 124-126.

Ragasa C. (2008). A comparison of computer assisted introduction and the traditional method of teaching basic statistics. Journal of Statistics Education 16: 1.

Reid A. and Petocz, P. (2003). Enhancing academic work through the synergy between teaching and research. International Journal of Academic Development 8: 111-123.

Reid A. and Petocz P. (2002). Students' conceptions of statistics: A phenomenographic study. Journal of Statistics Education 10.

Schutz P., Drogosz L., White V., Distefano C. (1998). Prior knowlwdge, attitude, and strategy use in an introduction to statistics course. Learning and Individual Differences, 10, 291-308.

Slotnick H. (1993). Teaching Bayes' theorem using paper dolls. ASA Proceedings of the Section on Statistical Education. American Statistical Association (Alexandria, VA): 127-131.

Weinberg S. and Abramowitz S. (2003). Data Analysis for the Behavioral Sciences Using SPSS. Journal of Educational and Behavioral Statistics 28: 83-88.

West, Charles K., Farmer J. and Wolff P. (1991). Instructional Design: Implications from Cognitive Science, Allyn and Bacon, Boston, Massachusetts. 